\title{
BMJ Open Effects of individual, family and community factors on the willingness of institutional elder care: a cross-sectional survey of the elderly in China
}

\author{
Zhaoqing Wang, ${ }^{1}$ Yanan Xing, ${ }^{1,2}$ Wenxin Yan, ${ }^{1}$ Xinran Sun, ${ }^{1}$ Xueying Zhang, ${ }^{1}$ \\ Shuang Huang, ${ }^{1} \mathrm{Li} \mathrm{Li}$ (D) ${ }^{1}$
}

To cite: Wang Z, Xing Y, Yan W, et al. Effects of individual, family and community factors on the willingness of institutional elder care: a cross-sectional survey of the elderly in China. BMJ Open 2020;10:e032478. doi:10.1136/ bmjopen-2019-032478

- Prepublication history for this paper is available online. To view these files, please visit the journal online (http://dx.doi. org/10.1136/bmjopen-2019032478).

ZW and YX contributed equally.

Received 20 June 2019 Revised 29 November 2019 Accepted 17 December 2019

A) Check for updates

(c) Author(s) (or their employer(s)) 2020. Re-use permitted under CC BY-NC. No commercial re-use. See rights and permissions. Published by BMJ.

${ }^{1}$ Department of Health Management, School of Health Management, Harbin Medical University, Harbin, Heilongjiang, China

${ }^{2} \mathrm{SHS} B G / H 06$, BOE Health Investment Management, Beijing, China

Correspondence to

Professor Li Li;

healthlaw@126.com

\section{ABSTRACT}

Objective To investigate the effects of the willingness to live in elder care institutions associated with individual factors, family environment and the community environment in the elderly in China.

Design Cross-sectional survey.

Setting Heilongjiang Province, China.

Participants A total of 1003 elderly people were selected through multistage sampling in Heilongjiang Province.

Primary and secondary outcome measures $A$ multistage, stratified sampling design was employed. Differences in health status, family environment and community environment of the respondents were compared with the t-test and $\chi^{2}$ test. Logistic regression analysis was performed to assess key determinants of willingness to live in institutions.

Results This study showed that $45.4 \%$ of respondents were willing to live in elder care institutions in the future. Factors influencing willingness to live in elder care institutions were age, house ownership, living with spouse and children, disease caregivers and availability of home healthcare services. The elders who had no property $(0 \mathrm{R}=2.37,95 \% \mathrm{Cl} 1.750$ to $3.200, \mathrm{p}<0.01)$ and those aged 80 or above $(\mathrm{OR}=2.25,95 \% \mathrm{Cl} 1.490$ to $3.400, \mathrm{p}<0.01)$ were, respectively, 2.370 and 2.250 times more receptive to living in elder care institutions than their control groups. However, those living with a spouse $(\mathrm{OR}=0.47,95 \% \mathrm{Cl}$ 0.287 to $0.762, p<0.01)$, living with children $(0 R=0.25$, $95 \% \mathrm{Cl} 0.158$ to $0.402, \mathrm{p}<0.01$ ) or living with a spouse and children $(\mathrm{OR}=0.29,95 \% \mathrm{Cl} 0.160$ to $0.509, \mathrm{p}<0.01)$ were less willing to live in elder care institutions.

Conclusions These results suggest that the willingness to enter elder care institutions is affected by individual, family environmental and community environmental factors. We should vigorously develop community-centred intensive home-based elder care services by improving the quality and availability of home health services by expanding investment in the community.

\section{INTRODUCTION}

The ageing population has become a worldwide phenomenon, and concerns with the issue of elder care have been expanding globally. The situation of elder care has been very problematical in China, where
Strengths and limitations of this study

We carried out a comprehensive study that selected factors related to individuals, family environment and community environment as potential factors which may affect the willingness to accept institutional elder care.

- The samples were selected through multistage sampling.

- We selected participants from a single province.

- The small sample size in our study limits the generalisability of the findings.

- We used a cross-sectional design; therefore, no causal relationships can be identified.

the one-child policy was enforced for over 30 years. ${ }^{1}$ According to Chinese official data, by the end of 2017, a total of 158310000 persons were aged 65 or older, accounting for $11.4 \%$ of the total population. ${ }^{2}$ Meanwhile, 40.63 million disabled elderly people lived in China, making up $18.3 \%$ of the aged population. ${ }^{3}$

Chinese society's economy, social welfare and social security systems are unable to cope with the pressure of the ageing population. Introduced in the 1980s, the one-child policy, which meant that a couple can have only one child, was enforced for over 30 years. People who were born at the beginning of the onechild policy are now the main providers of elder care for their parents. In this so-called 4:2:1 phenomenon, each young parent is usually responsible for two pairs of grandparents, besides having the duty to raise their children. ${ }^{45}$ Therefore, too much pressure has been put on Chinese families. In addition, the number of elder care institutions, the quality of elder care workers and the services provided for the elderly all lag behind the diversified needs of the elderly population. ${ }^{67}$ 
Obviously, it is necessary to conduct research on elder care problems.

The Chinese government has introduced many policies and invested a large amount of money to erase the pressure on elder care, and has proposed two slogans: 'Active aging' and 'Healthy aging. ${ }^{8}$ Topics related to elder care have been paid much attention by the government and researchers. The extensive literature about elder care can be divided into four categories.

First, some researchers have focused on the health and quality of life of the elderly. ${ }^{9-11}$ They have found that the quality of life in the elderly population is affected by many factors, including individual, community and societal variables. Second, some studies of long-term care (LTC), which can effectively solve the pressure of social old age care, found that most countries are ill prepared in system or law to satisfy the demand for LTC. ${ }^{12} 13$ Third, research has shown that the living arrangements of the elderly have an important influence on their mental health. ${ }^{14} 15$

Finally, plenty of literature has focused on the factors influencing the willingness to receive elder care. Some studies have assessed the relationship between social support for the elderly and the willingness to receive elder care in China. ${ }^{16} 17$ Another study analysed the different factors influencing willingness to receive elder care from the perspective of intergenerational relations and social economic status. ${ }^{18}$ This indicated that the more harmonious the intergenerational relationship, the lower the willingness of the elderly to enter an institution. Meanwhile, the higher the social economic status, the more likely the elderly are to choose institutional elder care. Some researchers have studied the influence of the community environment on the willingness to receive elder care ${ }^{1920}$ One study showed that the quality of the community environment had a positive effect on the degree of satisfaction with community elder care. ${ }^{21}$

We believe that the internal characteristics of a person, such as health status, income and age, and the external factors, such as family members and community environment, affect the willingness of the elderly to receive elder care. It is worth mentioning that China is currently implementing a policy called the 'community family physician model', which can promote the accessibility of community health management and care services for the elderly. The main duty of the family physician is to carry out health management for community residents, especially chronic disease management and health recovery for the elderly. Whether to choose institutional elder care indicates whether old people are willing to leave their familiar environment, which can give them various kinds of support such as disease care, and physical and mental company. The influences of personal factors and external factors on the willingness to accept elder care are not isolated. Our study included the following aspects of the elderly: individual characteristics, family environment and community environment. In view of the newly launched policy 'family physician model', which has been studied only rarely, we have taken the 'Availability of home health care' as an aspect of the study. Our research is pioneering in the study of the willingness to accept care for the elderly with regard to three aspects: the individual, family and community.

The present study aimed: (1) to describe the status quo and compare the willingness to use institutional elder care according to individual characteristics, family environment and community environment; (2) to analyse the effects of individual, family and community factors on the willingness to accept institutional elder care.

\section{METHODS}

\section{Data and sample}

A cross-sectional survey of elderly individuals was conducted from 1 March to 31 August 2016 in Heilongjiang Province, China. First, those aged 60 years and above having the ability and being willing to answer the questions were included as our sample. Second, to make our sample as representative as possible, we employed a multistage stratified sampling design. We chose urban and rural samples, each accounting for about 50\%. Third, three cities, Harbin, Qiqihar and Jiamusi, were selected on the basis of their gross domestic product. Three communities and three villages were selected in each sampled city according to economic factors. In total, nine communities and nine villages were selected. In addition, in order to ensure that the elderly understood the questionnaire correctly, we used the face-to-face interview format during the investigation.

\section{Data collection}

The data were collected through face-to-face interviews using a structured questionnaire conducted by trained undergraduate and graduate students from Harbin Medical University. A total of 1200 questionnaires were distributed; 1003 (83.6\%) valid questionnaires were returned.

\section{Assessment tools}

The study's instrument was a self-administered questionnaire composed of five sections. Section 1 consisted of the participants' demographic characteristics including residence, gender, age, income, house ownership and culture. Among these variables, residence was composed of rural and urban, income was represented by five levels: <500, 500-999, 1000-1999, 2000-3000 and >3000 monthly, and culture was divided into five dimensions: no education, primary school, junior high school, senior high school and college degree or above.

Section 2 measured the health status of respondents. Physical health was assessed by self-rated physical health and self-rated capacity. Higher scores indicate better health. The scores for each question ranged from 1 to 5 . Psychological health status was assessed by life satisfaction and feeling of isolation.

Section 3 assessed the family environment of the respondents. Family environment included whether he/she 
had living children, marital status, living arrangements, disease caregiver and parent-child relationships. Living arrangements were investigated using three questions: 'Are you living with your spouse?', 'Are you living with your children?' and 'Are you living with others?' Based on the answers, we classified living arrangements into four groups: (1) living alone, (2) living with spouse (may have others), (3) living with children (may have others) and (4) living with children and spouse (may have others). Because no participants in our sample were living with others only (not spouse or children), we ruled out this situation. Disease caregiver was divided into five groups: spouse, child, other relatives, nursing workers and themselves. The parent-child relationship was rated good, normal and bad.

Section 4 assessed the community environment of the respondents. This section included two questions: availability of community recreational facilities and availability of home healthcare services. Each question's score ranged from 1 to 5 , and high scores indicate high availability.

Section 5 assessed willingness to live in an institution. The variable 'Willingness to live in institution' was indicated by the question 'Which are you willing to accept out of home care and institutional care?' The respondents were allowed to consider whether they wanted to go to an institution or stay at home for elder care when needed.

\section{Data analysis}

The data were analysed using the Statistical Program for the Social Sciences (SPSS) V.17.0. Descriptive analyses included frequencies and percentages for the categorical variables and means and SDs for continuous variables. Differences in health status, family environment and community environment for respondents were compared with the t-test and $\chi^{2}$ test. Logistic regression analysis was performed to assess key determinants of the willingness of elderly people to live in institutions. Statistical significance was set at the $5 \%$ level.

\section{Patient and public involvement}

This study did not involve patients and the public in the design or planning of the study.

\section{RESULTS}

\section{Socioeconomic and demographic status of respondents}

The socioeconomic and demographic characteristics of the respondents are shown in table 1 . More than half of the respondents were female $(52.7 \%)$, urban $(57.9 \%)$ and married $(59.4 \%)$. A majority of the participants have children $(94.7 \%)$ and own a house $(61.3 \%)$. About half of them $(52.0 \%)$ were educated to a lower level than that of junior high school. Only $31.2 \%$ of them had monthly incomes above $¥ 2000$. Seventy-two per cent of them were able to support themselves financially. In this survey, $51.0 \%$ of the respondents were aged between 60 and 69 years, and $27.9 \%$ were aged between 70 and 79 years. Table 1 shows that $48.4 \%$ of urban older adults and $41.0 \%$ of
Table 1 Analysis of the willingness to live in elder care institutions according to individual characteristics of the respondents

\begin{tabular}{|c|c|c|c|c|}
\hline \multirow[b]{2}{*}{ Variables } & \multicolumn{2}{|c|}{ Total } & \multicolumn{2}{|c|}{$\begin{array}{l}\text { Willingness to live in } \\
\text { elder care institutions }\end{array}$} \\
\hline & $\mathbf{n}$ & $\%$ & $\mathbf{n}$ & $\%$ \\
\hline \multicolumn{5}{|l|}{ Residence } \\
\hline Urban & 581 & 57.9 & 281 & 48.4 \\
\hline Rural & 422 & 42.1 & 173 & 41.0 \\
\hline$\chi^{2}$ & & & 5.36 & \\
\hline$P$ value & & & 0.02 & \\
\hline \multicolumn{5}{|l|}{ Sex } \\
\hline Male & 474 & 47.3 & 215 & 45.4 \\
\hline Female & 529 & 52.7 & 239 & 45.2 \\
\hline$\chi^{2}$ & & & 0.00 & \\
\hline$P$ value & & & 1.00 & \\
\hline \multicolumn{5}{|c|}{ Age (years) } \\
\hline $60-69$ & 508 & 51.0 & 188 & 37.0 \\
\hline $70-79$ & 280 & 27.9 & 122 & 43.6 \\
\hline$\geq 80$ & 215 & 21.1 & 144 & 67.0 \\
\hline$\chi^{2}$ & & & 55.21 & \\
\hline$P$ value & & & $<0.001$ & \\
\hline
\end{tabular}

\begin{tabular}{|c|c|c|c|c|}
\hline \multicolumn{5}{|c|}{$\begin{array}{l}\text { Monthly income } \\
(¥)\end{array}$} \\
\hline$<500$ & 314 & 31.3 & 124 & 39.5 \\
\hline 500-999 & 125 & 12.5 & 55 & 44.0 \\
\hline 1000-1999 & 251 & 25.0 & 124 & 49.4 \\
\hline $2000-3000$ & 197 & 19.6 & 95 & 48.2 \\
\hline$>3000$ & 116 & 11.6 & 56 & 48.3 \\
\hline$\chi^{2}$ & & & 7.16 & \\
\hline$P$ value & & & 0.12 & \\
\hline \multicolumn{5}{|c|}{ House property } \\
\hline Yes & 615 & 61.3 & 221 & 35.9 \\
\hline No & 388 & 38.7 & 233 & 60.1 \\
\hline$\chi^{2}$ & & & 55.85 & \\
\hline$P$ value & & & $<0.001$ & \\
\hline
\end{tabular}

Financial

independence

\begin{tabular}{|lllll}
\hline Yes & 725 & 72.3 & 346 & 47.7 \\
\hline No & 278 & 27.7 & 108 & 38.8 \\
\hline$\chi^{2}$ & & & 6.39 & \\
\hline P value & & & 0.01 & \\
\hline Education & & & & \\
\hline $\begin{array}{l}\text { No education } \\
\text { Primary school }\end{array}$ & 195 & 19.4 & 85 & 43.6 \\
$\begin{array}{l}\text { Junior high } \\
\text { school }\end{array}$ & 288 & 28.7 & 132 & 45.8 \\
$\begin{array}{l}\text { Senior high } \\
\text { school }\end{array}$ & 118 & 11.8 & 55 & 46.6 \\
\hline
\end{tabular}

Continued 
Table 1 Continued

\begin{tabular}{|c|c|c|c|c|}
\hline \multirow[b]{2}{*}{ Variables } & \multicolumn{2}{|c|}{ Total } & \multicolumn{2}{|c|}{$\begin{array}{l}\text { Willingness to live in } \\
\text { elder care institutions }\end{array}$} \\
\hline & $\mathbf{n}$ & $\%$ & $\mathbf{n}$ & $\%$ \\
\hline $\begin{array}{l}\text { College degree } \\
\text { or above }\end{array}$ & 75 & 7.5 & 31 & 41.3 \\
\hline$\chi^{2}$ & & & 0.92 & \\
\hline$P$ value & & & 0.92 & \\
\hline
\end{tabular}

Bold values emphasize the statistical significance.

rural older adults preferred elder care institutions. There were significant differences in the percentage willingness to live in elder care institutions according to urban area $(\mathrm{p}<0.05)$, age $(\mathrm{p}<0.01)$, house ownership $(\mathrm{p}<0.01)$ and financial independence $(\mathrm{p}<0.05)$. Older adults who have their own house and have no financial independence had lower willingness to enter elder care institutions than those who have no house ownership. The respondents aged 80 or above had the highest willingness to enter an elder care institution, followed by those aged 70-79 and aged 60-69 years.

\section{Willingness to live in elder care institutions according to family environment}

Table 2 shows that participants who have children $(\mathrm{p}<0.01)$ and/or have a spouse $(\mathrm{p}<0.01)$ have lower willingness to live in elder care institutions. It is worth mentioning that our results showed that children were negatively correlated with the willingness to live in an elder care institution $\left(\chi^{2}=18.1, \mathrm{p}<0.01\right) \quad(\mathrm{OR}=7.52,95 \%$ CI 3.310 to $17.120, p<0.05$ ), which means that the elderly who have children were 7.52 times less willing to live in elder care institutions than the elderly who have no child. Regarding living arrangements, older adults living alone have the strongest willingness to live in an elder care institution, followed by those living with a spouse, living with children and living with spouse and children $(\mathrm{p}<0.01)$. The willingness to enter elder care institutions among the elderly who were nursed by nursing workers was higher than for those who were nursed by a spouse, children and/or other relatives $(\mathrm{p}<0.01)$.

\section{Willingness to live in elder care institutions according to health status}

We used self-rated physical health, life satisfaction, feeling of isolation and self-rated capacity for action to evaluate the health status of the respondents (table 3). The mean scores for self-rated physical health and selfrated capacity for action were 3.30 and 3.54, respectively, which were slightly higher than the midpoint of 3 . The life satisfaction was 5.08, which indicated high well-being among the elderly. The feeling of isolation was at a relatively low level $(\mathrm{M}=3.54, \mathrm{SD}=0.96)$. Among these four variables, only self-rated capacity for action was significantly different between those preferring home care and those willing to receive institutional care: the participants
Table 2 Analysis of the willingness to live in elder care institutions according to the family environment of the respondents

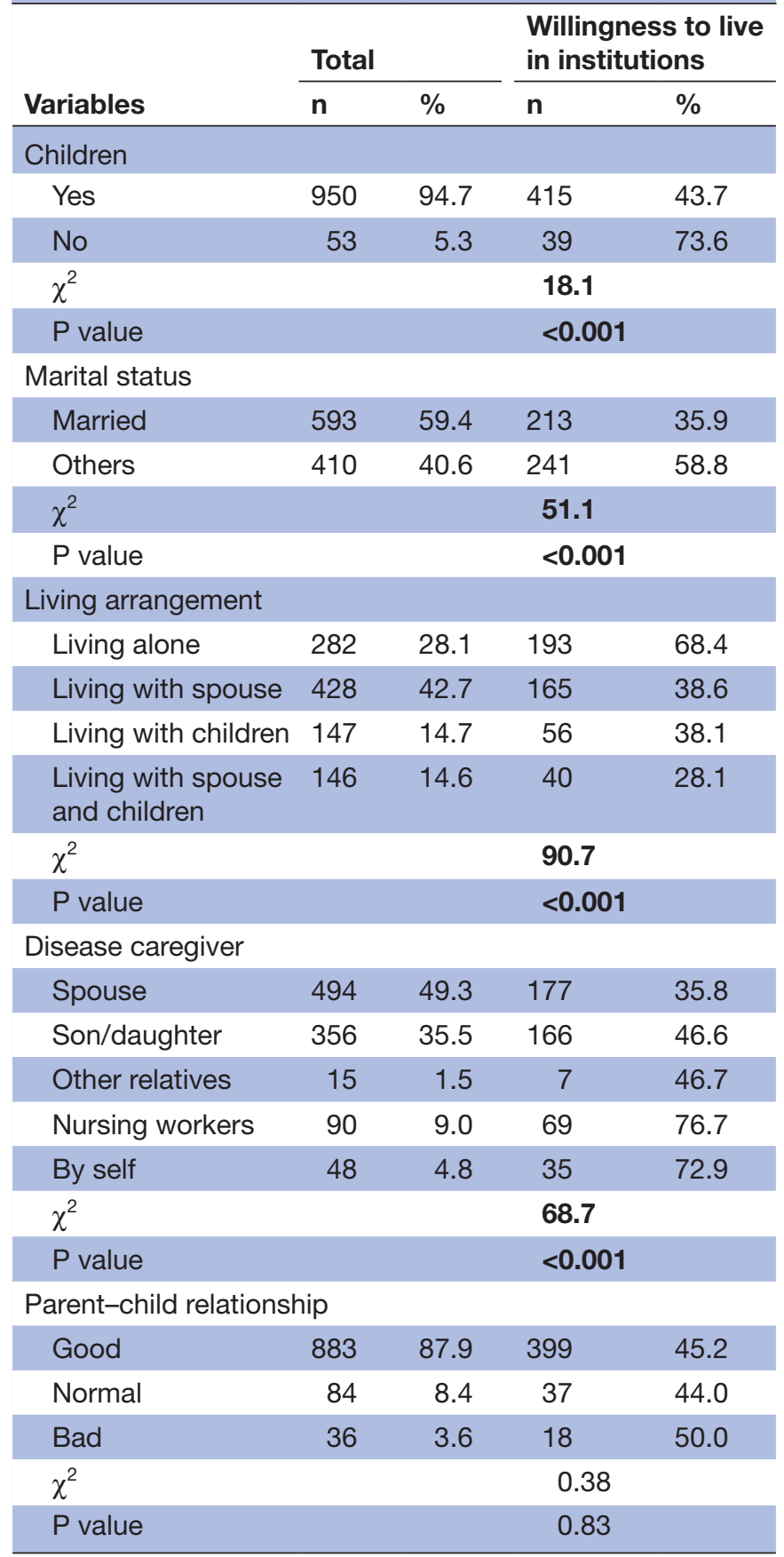

Bold values emphasize the statistical significance.

preferring home care had higher self-rated capacity for action $(\mathrm{M}=3.61, \mathrm{SD}=0.94, \mathrm{p}=0.01)$.

\section{Willingness to live in elder care institutions according to community environment}

The mean scores for self-assessed availability of community recreational facilities and availability of home healthcare services were 3.72 and 3.25 , respectively (table 4 ). Statistically significant differences were noted in the scores on both of these variables between those who preferred 
Table 3 Analysis of the willingness to live in elder care institutions according to the health status of the respondents

\begin{tabular}{lllllll} 
Variables & $\begin{array}{l}\text { Mean } \pm \text { SD } \\
(\mathbf{n}=\mathbf{1 0 0 3})\end{array}$ & $\begin{array}{l}\text { Range of } \\
\text { the score }\end{array}$ & $\begin{array}{l}\text { Home care } \\
(\mathbf{n}=\mathbf{5 4 8})\end{array}$ & $\begin{array}{l}\text { Institutional } \\
\text { care }(\mathbf{n}=\mathbf{4 5 5})\end{array}$ & $\mathbf{T}$ & $\mathbf{P}$ value \\
\hline Self-rated physical health & $3.30 \pm 0.97$ & $1-5$ & $3.28 \pm 1.00$ & $3.33 \pm 0.94$ & 0.80 & 0.42 \\
Life satisfaction & $5.08 \pm 1.27$ & $1-7$ & $5.13 \pm 1.25$ & $5.03 \pm 1.28$ & 1.21 & 0.23 \\
Feeling of isolation & $1.91 \pm 0.77$ & $1-5$ & $1.91 \pm 0.76$ & $1.91 \pm 0.78$ & 0.15 & 0.88 \\
Self-rated capacity for action & $3.54 \pm 0.96$ & $1-5$ & $3.61 \pm 0.94$ & $3.45 \pm 0.98$ & 2.59 & $\mathbf{0 . 0 1}$ \\
\hline
\end{tabular}

Bold values emphasize the statistical significance.

home care and those who favoured institutional care; those who preferred home care reported higher scores for the availability of community recreational facilities and the availability of home healthcare services $(p<0.05)$.

\section{Factors influencing willingness to live in elder care institutions}

In this study, $45.4 \%$ of respondents said they were willing to live in elder care institutions at some point in the future. Based on the results of single factor analysis, logistic regression was conducted to analyse the factors influencing the willingness to live in elder care institutions (table 5). Regarding the individual factors, only age in years and house ownership were predictors of the willingness to enter institutions. The elders who had no property $(\mathrm{OR}=2.37, \mathrm{p}<0.01)$ and those aged 80 or above $(\mathrm{OR}=2.25, \mathrm{p}<0.01)$ were, respectively, 2.370 and 2.250 times more receptive to living in elder care institutions than their control groups. With regard to living arrangements, those living with a spouse $(\mathrm{OR}=0.47, \mathrm{p}<0.01)$, living with children $(\mathrm{OR}=0.25, \mathrm{p}<0.01)$ or living with a spouse and children $(\mathrm{OR}=0.29, \mathrm{p}<0.01)$ were less willing to live in elder care institutions than those who were living alone. These results meant that the elderly who live with a spouse were 0.468 times more willing to choose institutional elder care than those who were living alone. We also found that elders who were cared for by their children $(\mathrm{OR}=0.33, \mathrm{p}<0.01)$ or cared for by their spouse $(\mathrm{OR}=0.40$, $\mathrm{p}<0.01)$ when they were ill had much lower willingness to live in elder care institutions than those who cared for themselves. The availability of home healthcare services $(\mathrm{OR}=0.78, \mathrm{p}<0.05)$ was negatively associated with the willingness to live in elder care institutions.

\section{DISCUSSION}

This cross-sectional study was conducted to explore the key factors contributing to the willingness to enter elder care institutions. This study was a pioneering one because we took the willingness to live in elder care institutions as the dependent variable and chose independent variables from three dimensions: individual factors, family environment and community environment.

With regard to individual factors, both the single factor analysis (table 1) and the logistic regression (table 5) demonstrated that age and house ownership were significantly associated with the willingness to live in an elder care institution. People in their $80 \mathrm{~s}$ and above had 2.250 times more willingness to live in elder care institutions than the group aged 60-69 years. The same conclusion was drawn from another study. ${ }^{22}$ Another study pointed out that those in advanced old age are much more likely to have elder care needs, including physical and psychological. ${ }^{23}$ Given that most of these needs cannot be met by family, the willingness to accept institutional elder care rises with age. Second, when analysing house ownership and the willingness to enter institutional elder care, we found that when the elderly have their own house, they have a significantly lower willingness to accept institutional elder care than those who have no property. The elderly in China traditionally intend to live the rest of their life in their own house because they regard their own houses as their roots of life. Having their own houses gives the Chinese elderly a great sense of belonging, as a study found that the sense of comfort and freedom when receiving elder care in their own houses is irreplaceable by other methods. ${ }^{24}$ A similar conclusion was reached by other studies, which demonstrated that house ownership is highly correlated with current health status and is predictive of future mortality risk in older populations. $^{2526}$ However, statistical significance of the impact of the independent variable residence on the dependent variable (the willingness to live in elder care institutions) was found only with $\chi^{2}$ tests (table $1, \chi^{2}=5.36, p<0.05$ ) and not in logistic regression, as shown in many studies. ${ }^{27} 28$

Table 4 Analysis of the willingness to live in elder care institutions according to the community environment of the respondents

\begin{tabular}{|c|c|c|c|c|c|c|}
\hline Variables & $\begin{array}{l}\text { Mean } \pm S D \\
(n=1003)\end{array}$ & $\begin{array}{l}\text { Range of } \\
\text { the score }\end{array}$ & $\begin{array}{l}\text { Home care } \\
(n=548)\end{array}$ & $\begin{array}{l}\text { Institutional } \\
\text { care }(n=455 \text { ) }\end{array}$ & $\mathbf{T}$ & $P$ value \\
\hline Availability of community recreation facility & $3.72 \pm 0.74$ & $1-5$ & $3.76 \pm 0.74$ & $3.67 \pm 0.74$ & 2.00 & 0.046 \\
\hline Availability of home healthcare services & $3.25 \pm 0.69$ & $1-5$ & $3.29 \pm 0.71$ & $3.20 \pm 0.66$ & 2.15 & 0.032 \\
\hline
\end{tabular}


Table 5 Logistic regression analysis of the factors influencing willingness to live in elder care institutions

\begin{tabular}{|c|c|c|}
\hline Variables & $\begin{array}{l}\text { Adjust } \\
\text { OR }\end{array}$ & $95 \% \mathrm{Cl}$ \\
\hline \multicolumn{3}{|c|}{ Residence (Reference: Urban ) } \\
\hline Rural & 0.96 & 0.700 to 1.320 \\
\hline \multicolumn{3}{|c|}{$\begin{array}{l}\text { Age in years (Reference: } \\
60-69 \text { ) }\end{array}$} \\
\hline 70-79 & 1.02 & 0.730 to 1.430 \\
\hline$\geq 80$ & $2.25^{\star *}$ & 1.490 to 3.400 \\
\hline \multicolumn{3}{|c|}{ House property (Reference: Yes ) } \\
\hline No & $2.37^{\star \star}$ & 1.750 to 3.200 \\
\hline \multicolumn{3}{|c|}{$\begin{array}{l}\text { Financial independence } \\
\text { (Reference: Yes ) }\end{array}$} \\
\hline No & 0.85 & 0.590 to 1.210 \\
\hline \multicolumn{3}{|c|}{ Children (Reference: Yes ) } \\
\hline No & $7.52^{\star *}$ & 3.310 to 17.120 \\
\hline
\end{tabular}

Marital status (Reference:

Married)

Others

0.73

0.330 to 1.630

Living arrangement (Reference: Living

alone)

\begin{tabular}{|c|c|c|}
\hline Living with spouse & $0.47^{\star *}$ & 0.287 to 0.762 \\
\hline Living with children & $0.25^{\star \star}$ & 0.158 to 0.402 \\
\hline $\begin{array}{l}\text { Living with spouse and } \\
\text { children }\end{array}$ & $0.29^{\star *}$ & 0.160 to 0.509 \\
\hline \multicolumn{3}{|c|}{ Disease caregiver (Reference: By self) } \\
\hline Spouse & $0.40^{* *}$ & 0.180 to 0.903 \\
\hline Son/daughter & $0.33^{\star *}$ & 0.158 to 0.684 \\
\hline Other relatives & 0.48 & 0.131 to 1.760 \\
\hline Nursing workers & 0.80 & 0.337 to 1.904 \\
\hline $\begin{array}{l}\text { Self-rated capacity for } \\
\text { action }\end{array}$ & 1.01 & 0.860 to 1.180 \\
\hline $\begin{array}{l}\text { Availability of community } \\
\text { recreation facility }\end{array}$ & 1.03 & 0.830 to 1.280 \\
\hline $\begin{array}{l}\text { Availability of home } \\
\text { healthcare services }\end{array}$ & $0.78^{*}$ & 0.626 to 0.972 \\
\hline
\end{tabular}

${ }^{*} \mathrm{P}<0.05 ;{ }^{* *} \mathrm{P}<0.01$.

However, our result was similar to a previous study. ${ }^{29} \mathrm{We}$ assume that, as the trend of urban-rural integration advances, the difference between urban and rural areas is not strong enough to show statistically significant differences when compared with other variables such as age and house ownership.

Family environment also comprised some typical factors influencing willingness to live in elder care institutions. This study showed that the elderly who have children were 7.52 times less willing to live in elder care institutions than those who have no children. This meant that children were negatively correlated with the willingness to live in elder care institution. In addition, we found that the elderly who lived alone and those who cared for themselves when they had diseases both had the highest willingness to live in elder care institutions. Undeniably, Chinese-grown children nowadays are facing great pressure because of the so-called '4-2-1' family structure and the interpersonal tensions and work-family conflict created by the advent of globalisation and fierce market competition. ${ }^{30}$ However, a published review indicated that adult children still endorse filial piety in contemporary Chinese society. ${ }^{32}$ This result was consistent with many studies in which the elderly showed less willingness to live in elder care institutions when they have children. ${ }^{33} 34$ As the well-known proverb 'raising children to ensure elder care' indicates, in Chinese traditional culture, filial piety demands that, apart from economic and living care, psychological care should also be provided for elderly parents. ${ }^{35}$ Some previous studies have pointed out that adult children who have placed their parents in elder care homes may be negatively regarded by society. ${ }^{36} 37$ This study showed that the elderly who lived alone had the highest willingness to live in elder care institutions. We assume that the elderly living alone typically lack physical and psychological assistance and care from their family, and are therefore more willing to live in elder care institutions. Similar results were found in a study that showed that elderly people who lived alone were more willing to live in elder care institutions, for both single males and females, when compared with those who lived with children or others. ${ }^{38}$ First, as another study concluded, older people are more likely than any other section of the population to be living in single-person households. ${ }^{39}$ Second, the elderly who live alone have higher scores for loneliness and worse mental health and functioning compared with those who do not live alone. ${ }^{40}$ Third, a Korean study found that physical health status, self-esteem, family support and health-promoting behaviour, specifically exercise and nutrition, of the elderly living with family were higher than those of the elderly living alone. ${ }^{42}$

With an increase in age, physical health tends to deteriorate, so we included disease caregiver in our research. Our analysis showed significant differences among five disease caregivers: spouse, son or daughter, other relatives, nursing workers and the elderly person themselves; $86.24 \%$ of respondents were provided with disease care by their immediate family members or other relatives. This means that informal care is the main form of care for the elderly in China. A study in Europe showed that informal care is an effective substitute for LTC as long as the needs of the elderly are met. ${ }^{43}$ In support, in our study the lowest willingness to accept elder care institutions was shown by the elderly cared for by their spouse. A study demonstrated that a spouse can give the elder physical and, especially, mental care, thus their willingness to live in elder care institutions was lower than that of those who have no spouse. ${ }^{44}$ In the multiple logistic regression analysis, we found that when the elderly were provided with disease care by their spouse or children, their willingness to live in elder care institutions decreased. When the 
elderly have no children or live alone, they cannot obtain informal or formal care from family as desired, so they have to seek care from elder care institutions. Therefore, the primary culture of filial piety, the conditions of living and the presence of disease all affect the willingness of the elderly to live in elder care institutions.

Last, but not least, we paid attention to the community environment. We found that the availability of home healthcare services negatively affected the willingness to live in elder care institutions, in agreement with previous studies. ${ }^{45}{ }^{46}$ In China, home healthcare services are mostly provided by institutions called elder care community centres, such as community health service centres. One study showed that these centres could increase willingness to accept home elder care. ${ }^{47}$ The research pointed out that high availability of home health services in the community provided the elderly with basic nursing services to meet their fundamental needs for care, and therefore lowered the willingness to accept institutional elder care. ${ }^{48}$ In our study, the mean availability of home healthcare services was 3.25 , which is much higher than the average level because of adoption of the model of community family physician. This new Chinese policy, the 'community family physician model', has aroused heated discussion among all types of people. Some researchers have found that this policy is associated with problems such as unclear responsibilities, high medical risk and lack of a security system. ${ }^{49}{ }^{50}$ However, some found that this policy did improve the convenience and success rate of medical treatment, thus improving the level of health of the signatories. ${ }^{5152}$ It is no doubt that home healthcare services have become more conveniently available for elderly residents.

However, several limitations in our study should be discussed. First, we used a cross-sectional design, in which data were collected at only one point in time. This may have caused information bias, including mainly recall bias and measurement bias. In order to reduce measurement bias, the investigators underwent rigorous training to improve their survey skills and our respondents were given enough time to recall. Second, our participants were from a single province and, therefore, we cannot generalise the results to assume that they apply to all of the elderly in China. In order to make our study more convincing, we will introduce more widely used measuring tools including Activities of daily living into our research and conduct the same research nationwide in future.

\section{CONCLUSION}

At present, in China, the enormous pressure of elder care has shifted increasingly from family to society, and it is difficult for institutions to take on the heavy burden of care. However, the tradition of filial piety in Chinese culture is restricting the willingness of the elderly to receive institutional elder care. Therefore, we should vigorously develop community-centred intensive homebased elder care services by improving the quality and availability of home health services by expanding investment in the community. Only in this way can we meet the need for both formal and informal elder care and the need to cater to the Chinese traditional morality.

Acknowledgements The authors thank all participants in this study. They also thank LL for her guidance on the writing of the manuscript. They thank the International Science Editing (http://www.internationalscienceediting.com) for editing this manuscript.

Contributors LL conceived and designed the experiments. ZW and WY performed the experiments. XS and XZ analysed the data. SH, YX and LL contributed reagents/ materials/analysis tools. ZW wrote the paper. ZW, WY and XS provided technical support. LL critically revised the paper. All authors checked and proofread the final version of the manuscript.

Funding This study was funded by the National Science Foundation of China (NSFC) and the China Postdoctoral Science Foundation (contract numbers 71573066/G0308 and 2018M631967).

Competing interests None declared.

Patient consent for publication Not required.

Ethics approval Ethics approval for this study was granted by the Institutional Research Board of Harbin Medical University. The data were collected anonymously. Respondents were assured that participation in this survey was voluntary, with the completion of the questionnaire being taken as consent to participate.

Provenance and peer review Not commissioned; externally peer reviewed.

Data availability statement No data are available.

Open access This is an open access article distributed in accordance with the Creative Commons Attribution Non Commercial (CC BY-NC 4.0) license, which permits others to distribute, remix, adapt, build upon this work non-commercially, and license their derivative works on different terms, provided the original work is properly cited, appropriate credit is given, any changes made indicated, and the use is non-commercial. See: http://creativecommons.org/licenses/by-nc/4.0/.

ORCID iD

Li Li http://orcid.org/0000-0002-6171-3691

\section{REFERENCES}

1 Chen L, Han W-J. Shanghai: Front-Runner of community-based eldercare in China. J Aging Soc Policy 2016;28:292-307.

2 CSY. China Statisticalstatistical Yearbook. Beijing: China Statistical Publishing House, 2018.

3 Ministry of Civil Affairs Portal. The three departments released the results of the fourth sampling survey on the living conditions of urban and rural elderly in China [EB/ OL]..

4 HD L, R W, YJ R. Analysis of the number of only children and family structure since the family planning policy. Statistics Decision 2018;13.

5 Hesketh T, Zhou X, Wang Y. The end of the one-child policy: lasting implications for China. JAMA 2015;314:1-2.

6 LB Q. The status quo and prospect of the development of China's old-age service industry. Journal of Fujian Party School 2016;3:75-83.

7 Nie J-B. Erosion of Eldercare in China: a Socio-Ethical Inquiry in Aging, Elderly Suicide and the Government's Responsibilities in the Context of the One-Child Policy. Ageing Int 2016;41:350-65.

$8 \mathrm{MY}$, AQ F. The construction of new community nursing home model from the perspective of active aging. Study and Practice 2018.

9 Mun S, Park K, Baek Y, et al. Interrelationships among common symptoms in the elderly and their effects on health-related quality of life: a cross-sectional study in rural Korea. Health Qual Life Outcomes 2016;14:146.

10 Sun W, Aodeng S, Tanimoto Y, et al. Quality of life (QOL) of the community-dwelling elderly and associated factors: a populationbased study in urban areas of China. Arch Gerontol Geriatr 2015;60:311-6.

11 C Y. Comparison of health status, social support and quality of life of elderly living alone and non-inhabited in Shanghai. Chinese $J$ Gerontol 2017;37.

12 Yeung W-JJ, Thang LL. Long-Term care for older adults in ASEAN plus three: the roles of family, community, and the state in addressing unmet eldercare needs. J Aging Health 2018;30:1499-515. 
13 Deusdad BA, Pace C, Anttonen A. Facing the challenges in the development of long-term care for older people in Europe in the context of an economic crisis. J Soc Serv Res 2016;42:144-50.

$14 \mathrm{Ya}$ J, Zhou F, Zhai ZE. The influence of residential patterns on the elderly's Depression-The Moderating role of community. Population Journal 2017;39:66-77.

15 Kwak Y, Chung H, Kim Y. Differences in health-related quality of life and mental health by living arrangement among Korean elderly in the KNHANES 2010-2012. Iran J Public Health 2017;46:1512-20.

16 Shi XP, Zhang HJ, Sui J. The investigation of long-term care mode selection and its influencing factors among disabled elder. Modern Prevent Med 2016;43:4467-70.

17 Liu XC, Yang LQ, Luo YY. Demand analysis for integrated medical and nursing care among community-dwelling elderly people based on Andersen's behavioral model. Chinese General Practice:1-8.

18 Liu EP, Zhang QL. Inter-Generational relations, socioeconomic status and preferences for institutional care of the Eldly--An empirical analysis based on China's longitudinal aging social survey (2012). Population Dev 2012;2018:55-64.

19 HU FX, LI MN, ZHANG D. Empirical study on rural elderly's demand will for patterns of pension service and its influencing Factors $-A$ case study from Shanxi Province. Journal of Xi'an Jiaotong University(Social Sciences) 2016;36:57-64.

20 SUN JJ, SHEN D. The Intention for the Old-age Support of the Chinese Elderly and Its Differences between Urban and Rural Elderly: A Study Based on the China Longitudinal Aging Social Survey. Population Economics 2017.

21 QIU L. Study on the influencing factors of the satisfaction of community old-age services: a case study of Shanghai. The World of Survey and Research 2016:15-18.

22 Qian Y, Qin W, Zhou C, et al. Utilisation willingness for institutional care by the elderly: a comparative study of empty nesters and nonempty nesters in Shandong, China. BMJ Open 2018;8:e022324.

23 Connolly S, O'Reilly D, Rosato M. House value as an indicator of cumulative wealth is strongly related to morbidity and mortality risk in older people: a census-based cross-sectional and longitudinal study. Int J Epidemiol 2010;39:383-91.

24 Wang $\mathrm{YH}$. Analysis for cause of the disability old people aid to Xinjiang choose long-term home care. Population and Development 2013;19:72-8.

25 Zhang Q, Zhang D. Study on select of pension methods of the elderly and its influencing factors in Beijing. Research on Economics and Management 2014;7:102-6.

26 Butterfield MC, Williams AR, Beebe T, et al. A two-county comparison of the houses index on predicting self-rated health. $J$ Epidemiol Community Health 2011;65:254-9.

27 HU B, ZHU B, LIU Y. Choices of old-age care and influence factors among empty nest elderly, Xuzhou. Modern Preventive Medicine 2018;45:90-4.

28 Liu H, Gao S, Wang J. The impact of Elder-Care patterns on Chinese elderly's health and well-being. (in Chinese. with english summary.). Economic Research Journal 2011.

29 Zhang D. A study on the aging willingness and influencing factors of the aged in Beijing's institutions. The World of Survey and Research 2017;2017:23-9.

30 Bhat MA, Rather TA. Socio-Economic factors and mental health of young people in India and China: an elusive link with globalization. Asian Social Work Policy Review 2012;6:1-22.

31 Simon MA, Chen R, Chang E-S, et al. The association between filial piety and suicidal ideation: findings from a community-dwelling Chinese aging population. The Journals of Gerontology Series A: Biological Sciences and Medical Sciences 2014;69:S90-7.
32 Dong X, Xu Y. Filial Piety among Global Chinese Adult Children: A Systematic Review. Research \& Reviews. Journal of Social Sciences 2016;2.

33 Zhang LW, Ceng YB, Ceng YB. Study on pension methods and its influential factors among the elderly by using Andersen behavior model. Chinese Journal of Health Statistics 2017;34:721-5.

34 W W L. Housing, aged care and migration: the housing careers of older Chinese migrants and its implicationslud. Oceania Regional Congress of Geriatrics \& Gerontology 2011

35 LV HP, LI ZG. Confucius'View of Filial Piety and the way of family pension. Population Research 2008;32:81-6.

36 Chen Z. Knowledge and perceptions: Chinese older adults willingness to use institutional elder care 2011.

37 Zhan HJ, Feng Z, Chen Z, et al. The role of the family in institutional long-term care: cultural management of filial piety in China. Int $J$ Soc Welf 2011;20:S121-34

38 Qian Y, Chu J, Ge D, et al. Gender difference in utilization willingness of institutional care among the single seniors: evidence from rural Shandong, China. Int J Equity Health 2017;16:77.

39 Rolls L, Seymour JE, Froggatt KA, et al. Older people living alone at the end of life in the U.K.: research and policy challenges. Palliat Med 2011;25:650-7.

40 Chen Y, Hicks A, While AE. Loneliness and social support of older people in China: a systematic literature review. Health Soc Care Community 2014;22:113-23.

41 Lim LL, Kua E-H. Living alone, loneliness, and psychological wellbeing of older persons in Singapore. Curr Gerontol Geriatr Res 2011;2011:673181.

42 Sok SR, Yun EK. A comparison of physical health status, selfesteem, family support and health-promoting behaviours between aged living alone and living with family in Korea. J Clin Nurs 2011;20:1606-12.

43 Bonsang $\mathrm{E}$. Does informal care from children to their elderly parents substitute for formal care in Europe? J Health Econ 2009;28:143-54.

44 Tian BH, Wang CY. Structural characteristics and determinant factors of the demand of the elderly for social care Services-based on the analysis on the replacement mechanism of family supporting for the elderly. China Rural Survey 2014;2:17-95.

45 DING JD. The Home Care Service:Recognizing Mistakes, Rational Principles and Perfecting Measures. Journal of Renmin University of China 2013;27:20-6.

46 JIE Y, Rosenberg MW, CHENG Y, Aging at home and the intent to relocate in Beijing. Geography 2015;34:1577-85.

47 Sun JJ, Shen D. The Intention for the Old-age Support of the Chinese Elderly and Its Differences between Urban and Rural Elderly:A Study Based on the China Longitudinal Aging SocialSurvey Population Eco 2017;2:11-20.

48 Zhang WJ, Meng W. A study on the factors associated with preferences for institutional care of the elderly in urban China: evidences from Xicheng district of Beijing. Population \& Economics 2014;6:22-34.

49 Ma W, Xu XG. Reflection on the perfection of signing service of family physician from the perspective of contract law. Chinese General Practice 2015;16:1980-3.

50 Wu SJ, Liu JR, Qiu S. Studying on the present situation of family doctor door-to-door service taking Guangzhou as an example. Chinese Primary Health Care 2015;29:1-3.

51 Chen JY, Jiang MX, Bao Y. Effect of family doctor contract service on health management of poor Elderlies in urban community. Chinese General Practice 2013;16:3355-7

$52 \mathrm{Lu} \mathrm{W}$, Zhang YM. The performance evaluation based on the demand side of the family doctor contract service: a focus on chronic diseases. Chinese Journal of Health Policy 2016;9:23-30. 